\title{
Docficção em Iracema, uma transa amazônica
}

Jorge Wolff (UFSC) ${ }^{1}$

É um cinema hipnótico, sem pernas. Não é vago.

Ana Cristina César, Luvas de pelica

1. Um documentáriofiç̧ão, um docficção. Uma história mal contada por um falso mentiroso. No cinema, tudo é literatura: dois personagens de distinta índole, gênero e idade varam a Amazônia em 1974, quando era proibido narrar. Entre a floresta, a estrada e a cidade, eles geram e são gerados por sua própria narrativa.

No marco de uma pesquisa que busca ler e reler, escrever e reescrever textos híbridos - isto é, ao mesmo tempo ficcionais e documentais -, a narrativa em foco é em vários sentidos fundamental. É o que se procura demonstrar a seguir.

2. Advertência anteposta ao filme quando de sua primeira apresentação em 1980 no Festival de Cinema de Brasília, do qual foi o grande vencedor:

Retratar a Transamazônica, de maneira realista, em 1974, representou um grande risco. As consequências foram anos de censura e de luta incessante para fazer o filme chegar ao público a que sempre se destinara. Iracema mostra, hoje, uma realidade que permanece tão urgente, senão mais, quanto o era na época quando a estrada ainda simbolizava um sonho do "Brasil Grande".

Essa história tá mal contada: se realismo há, é aquele que se excede em uma "ficção documental" que integra organicamente os seus dois termos - o imaginário e o empírico de maneira indiscernível ${ }^{2}$. Dois personagens "pegando estrada" sangram, cada um a sua maneira, a Amazônia. O que se vê a partir de seu encontro é a mais completa mistura de

\footnotetext{
${ }_{1}^{1}$ JORGE WOLFF (Porto Alegre, 1965) é mestre e doutor em Teoria Literária pela Universidade Federal de Santa Catarina e professor de graduação e pós-graduação em Literatura da mesma instituição. Autor de Julio Cortázar. A viagem como metáfora produtiva (Florianópolis: Letras Contemporâneas, 1998) e Telquelismos latinoamericanos. La teoría crítica francesa en el entre-lugar de los trópicos (Buenos Aires: Grumo, 2009). Tradutor de literatura argentina e francesa, é um dos editores da revista eletrônica Crítica Cultural.

2 SAER, 1992, p. 2
} 
documento e ficção, uma mistura que se dá literalmente: não há separação entre "quem atua" e "quem não atua", como ocorre de modo exemplar em Jogo de cena (2005), de Eduardo Coutinho, que tomo aqui como uma espécie de laboratório anacrônico do gênero híbrido docfição. Trato de entendê-los, portanto, como outra volta de parafuso daquilo que a crítica Josefina Ludmer ${ }^{3}$ chama de "realidadeficção", através da linguagem vizinha e outra do cinema.

Há duas maneiras, complementares, de entender o "grande risco" a que a advertência se refere: como temor à repressão que caracterizou aquele período da história brasileira; ou como o rastro que deixa toda imagem fílmica, a começar por aquela que pretende "retratar de maneira realista". Independente da retórica exterior ao relato fílmico, ele parece testemunhar precocemente - assim como o faz com relação à questão ecológica - que a relação das pessoas com a ficção estava em transformação, conforme observa o crítico Gonzalo Aguilar: "Ya no es entonces el ingreso en un mundo autónomo sino la búsqueda de los lazos con lo real y de ahí también que los filmes en tercera persona hayan hecho un uso cada vez más intenso del documento, de la imagen como documento". E agrega: "El

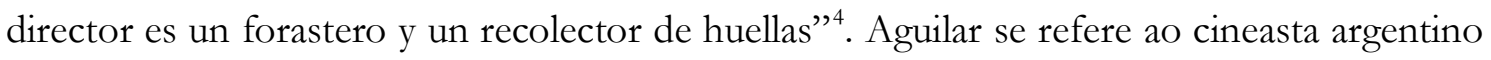
Lisandro Alonso, mas pode-se perfeitamente aplicar a frase aos diretores de Iracema: "Os diretores são uns forasteiros e uns colecionadores de rastros". Cruzam dois destinos e geram o relato a partir de seu encontro e do encontro deles com a gente dos rios, da cidade e da selva.

3. Assim como todo filme é também um documentário e toda conversa, uma forma de entrevista, toda narrativa, oral ou escrita, é uma história "mal contada", no sentido de que lhe falta algo e de que sempre lhe faltará alguma coisa (o que equivale a dizer que sempre lhe sobrará também). Mas o que se quer dizer quando se diz: "Essa história (documentada ou apenas entrevista) está mal contada”? Introduz-se o enigma e começa a investigação. Pensemos então na his-estória do filme Iracema, uma transa amazônica, de Jorge Bodanzky, Orlando Senna e Wolf Gauer (o produtor alemão), que sucede por água, terra (predominantemente) e ar (um voo de teco-teco rumo ao trabalho escravo). Pensemos esse relato mau nos moldes do "gênero bandido", para utilizar a expressão de Silviano Santiago 
a propósito do romance, "lawless por excelência", ou da "literatura mala" segundo César Aira $^{6}$, ambos em nome de uma narrativa - literária ou fílmica - sem qualidades, por definição precária e defeituosa. Numa palavra: má. O que significa simplesmente descontínua e decepcionante, recusando a sedução da referência ${ }^{7}$.

4. Histórias mal contadas, o livro de contos de Silviano Santiago publicado em 2005, sugere uma tradução malandra da expressão, na medida em que discute, no texto de abertura, a própria ideia de história mal contada em um formato de "autografia", em forma de ficção de si pela voz do narrador de "O envelope azul" (objeto ou "cronotopo" cuja história finalmente se conta). Fingidor consagrado, o escritor de Em liberdade e de O falso mentirosopara citar fingimentos de distintas épocas de sua trajetória - tem sido coerente com sua trajetória de hibridação do documental e do ficcional, ou seja, tem sido religiosamente fiel à infidelidade. Para ele, mal contar, fingir significa perder-ganhar: a alegria na dor. "Quantas histórias da minha vida foram mal contadas, e assim continuam”, começa o narrador ${ }^{8}$.

Ocorre que o narrador de "O envelope azul" exerce a função de colunista social - um especialista máximo, no mais das vezes, em histórias bem contadas, no sentido de enxutas e objetivas, histórias sem problemas, jamais comprometedoras, breves à maneira da comunicação boca a boca. A arte de aliciar: como se obtém vantagem escrevendo sobre o que me pagarem para escrever, de maneira rápida, textinhos repetidos aos milhões como um horóscopo da vida social, sem nenhuma preocupação com uma eventual cura através de uma escrita de si, ainda que disfarçada de coluna social. Ter-lhe-ia faltado empregar a escrita "etopoiética" de que fala Michel Foucault a propósito de Plutarco, enquanto "operador da transformação da verdade em ethos", da qual, no entanto e surpreendentemente, o narrador-colunista do extinto Jornal do Brasil mostra ser adepto. Questão de ética.

É esse mesmo narrador-colunista que faz, no "lero-lero" inicial (vão sete páginas e enfim se diz: "Chega de lero-lero. Vamos à história que selecionei","), uma "listagem das histórias

\footnotetext{
${ }^{5}$ SANTIAGO, 2002, p. 35

6 AIRA, 1991, p.47.

${ }^{7}$ cf. GRAMUGLIO, 2002, p. 11.

8 SANTIAGO, 2005, p. 11

${ }^{9}$ FOUCAULT, 1992 , p. 134

10 IDEM, p. 17.
} 
mal contadas". "São legião", ele acrescenta, esboçando logo no segundo parágrafo uma teoria por definição contraditória da história mal contada:

Que critérios adotar para escolher a primeira que receberá o crivo da verdade? Primeiro mandamento. Não cair no engodo de dar ouvidos ao desembaraço e à extroversão das histórias barulhentas e fétidas. As que se autodenominam mal contadas são na maioria dos casos as que receberam melhor tratamento por parte do narrador. Como se estivessem diante de um velho gagá, despem o traje de gala com que as vesti e comparecem ao tribunal da consciência aos andrajos. ${ }^{11}$

Ou seja, nunca é o que parece. O segundo mandamento reza: "A história escolhida tem de ser a mais silenciosa, intensa e obsessiva", isto é, ameaçadora, vingativa, podendo inclusive ser fatal. Mandamento diretamente vinculado ao de número quatro, que exige: tem de ser "história mal contada que não brinque em serviço". As próprias histórias ganham ares de personagem, afinal "o que importa quem fala" quando quem fala não é senão sua linguagem. O narrador-colunista dá então outra chave: “As intervenções inesperadas dos deuses, que carregam as histórias mal contadas para o ambiente festivo da minha cobertura, transformaram-me em especialista nos extravios narrativos. Narro em ziguezague. É o meu velho estilo. Em nada recomendável" ${ }^{\prime 12}$.

Pode-se concluir, portanto, que uma história mal contada é sempre narrada em ziguezague. É o caso de Iracema, uma transa amaðônica.

5. Easy rider brasileiro, o filme de Bodanzky, Senna e Gauer começa significativamente no escuro, apenas com o áudio do barulho de um barco a motor que conduz, entre outros locais, a menina Iracema, rumo a Belém. Ao lado da música e das mensagens de rádio, o tuc-tuc dos barcos é a trilha sonora comum dos ribeirinhos. Pelo rádio são marcados encontros e chegam notícias urgentes, como a que diz: "Fulano de tal, sua mãe amputou o lado da perna, mas está fora de perigo!” A câmera-na-mão capta, ziguezagueante, o banho no rio dos passageiros e o comércio de frutas e seu transporte. Também é significativo que a primeira fala do filme diga respeito às contas relativas à venda de um grande cesto de frutas: o comprador oferece ou, antes, impõe ao vendedor o valor de 64 cruzeiros mais

${ }^{11}$ Idem, p. 11.

${ }^{12}$ Idem. 
uma garrafa de cachaça - e estamos conversados. E o expectador já começa a se perguntar: o que dizem esses rostos? Rostos de corpos quase nus, sulcados pelo sol e pela sobrevivência, como o da própria menina que, ainda muito jovem, migra para a cidade e "cai na estrada", vale dizer, "na vida".

A vida na região, no início dos anos 70 , é por sua vez invadida e rasgada pelas motosserras - a extração de madeira de todos os tipos em uma terra sem lei. A partir do momento em que surge uma madeireira no filme, surge com ela - sobre ela, ao redor dela - a figura do caminhoneiro sulista Tião Brasil Grande (Paulo César Pereio), cujo roteiro atravessará aquele da bela Iracema e não o contrário, infelizmente: Iracema do século XX é sem ilusões. São os caminhos cruzados desses dois personagens o dispositivo-disparador e o motor dessa história mal contada.

6. Mas quem é afinal Tião Brasil Grande, rasgador de estradas e de corações Brasil afora, com suas costeletas, seus óculos escuros, sua camisa aberta no peito, suas calças boca-desino, suas sandálias e sua lábia ferina? O ponta-de-lança do filme não é, no entanto, nem índio nem africano, nem carioca nem baiano, mas um representante da espécie de bandeirantes sulistas modernos conhecida como "gaúchos" (sejam eles paulistas, paranaenses, catarinenses ou sul-riograndenses), a bordo de um caminhão com placas de Osório-RS, em nome do "Brasil: ame-o ou deixe-o". Sua atuação no filme é a de um cafajeste que pensa ser malandro e que quer fazer dinheiro à custa da Transamazônica e da extração de madeira, em nome do progresso irreversível do país.

“Meu nome é Sebastião da Silva. Sou gaúcho”. Através desse personagem vivido por um ator com o physique du rôle, um Paulo César Pereio tomado, ou seja, em seu estado de maior exaltação e inquietação, a viagem-narrativa promove uma incisão clandestina, um corte profundo na realidade da exploração da Amazônia brasileira na primeira metade dos anos 70, em plena euforia discursiva do Brasil Grande durante o regime militar. Esse corte que pouco a pouco se transforma em retalhamento é resultado da ação de um dispositivo dominante - o sulista branco - e da reação de um dominado - a indígena aculturada. $\mathrm{O}$ dominador-explorador faz intervenções entre populares, enquanto percorre a rodovia em construção a bordo de seu caminhão, nos portos, nos bares e bordéis por que passa, e essa atuação dispara a narrativa ao agregar a ela a própria prostituta chamada Iracema. 
A primeira intervenção entre populares - ou seja, entre não atores, habitantes nativos da região - introduz inteiro o personagem, e junto com ele o expectador, no torneio com as vozes do mundo a sua volta, aparecendo em todas suas contradições de imediato. É a fagulha que indistingue obra e vida, arte e experiência. Nessa intervenção inicial, Tião faz uma espécie de desafio com um barqueiro do porto de Belém, em que o senhor moreno e risonho de bigodinho faz o papel do pan-otimista simplório ("natureza é mãe", "Brasil é terra rica") e seu adversário no desafio o papel do provocador "civilizado": "Natureza é mãe coisa nenhuma", diz, em seus trajes e gírias modernas: "Eu sou o Tião Brasil Grande! Pode crer!" Discurso do contra feito em meio a risadas compartilhadas por conquistado e conquistador. "Estão apenas ensaiando?", se poderia perguntar (glosando o conto de Bernardo Carvalho).

O jargão político "dominante-dominado", "explorador-explorado" soa a anos 60-70 e bem a propósito (quer me parecer), já que o filme está neles profundamente mergulhado. Sim, trata-se também de um filme-denúncia financiado pela televisão pública alemã, que lança mão de dispositivos ficcionais especialmente eficazes (como viriam a se mostrar de maneira cada vez mais potente), a fim de documentar um determinado drama social, cultural, político e ecológico ocultado pela retórica oficial em torno da construção da rodovia Transamazônica, símbolo maior e grandiloquente do "absurdo Brasil". Autoridades aparecem em cena fazendo jus a essa retórica, em nome do que seria uma "indústria de eletricidade de porte mundial". "Exploremos nós, antes que os outros", diz o empreendedor "visionário" em cena em restaurante burguês, que chamativamente acrescenta: “A Volkswagen já está aí com fazenda de gado”.

7. Antes de se encontrarem, Tião e Iracema vão ao encontro da cidade, suas feiras, seus bichos e suas quinquilharias. Ele, agressivo e exultante, em diálogos com populares pelos bares em que a tônica é o slogan "Ninguém segura esse país". Ela, feliz e algo assustada na multidão, durante a Procissão do Círio de Nazaré. O policiamento é ostensivo e todos os discursos públicos - o do comandante da polícia, o do bispo e o da rádio "Liberal" - se dão em nome da "integração nacional”. Iracema passa da procissão à prostituição em um piscar de olhos: ela e uma amiga são vistas pelos bares e, em cena íntima, trocando roupas no quarto de um casebre. O discurso das amigas - como o de Tião, em outro sentido - é o de "correr terra". Nas ruas chamam a atenção as roupas coloridas e sumárias das mulheres, nos bares as pinturas naï nas paredes e a trilha sonora com direito a tangos e fandangos 
("Você é doida demais!"). Em um desses bares decrépitos, Tião Brasil Grande e Iracema finalmente se encontram, dançam e - como ocorre do início ao fim, apesar de seus papéis bem definidos - se provocam. Ela mente que tem 21 anos, ele a desmascara, chama de burra e - corte e solução de continuidade - os dois já estão na cabine do caminhão, viajando em pleno asfalto novo com um flamante Mercedes Benz. Da perspectiva da janela do caminhão, se veem então as queimadas em longa tomada (que, segundo Bodanzky, eram tão comuns que quase não foram filmadas).

Iracema pede 30 cruzeiros, Tião paga 20 pelo sexo com a indiazinha que nega ser índia: "Sou brasileira", diz, enquanto ele ri. E a viagem segue, o explorador vai à fonte da extração de madeira e negocia madeira de lei proibida. Enquanto isso, Iracema descansa em uma cabana e entrevista, por sua vez, a esposa do madeireiro, que conta suas mazelas, cheia de filhos e disposição para sair dali. Também Iracema funciona como disparadora de ficções documentais, seja através de sua língua, seja através de seu corpo: ei-la vestindo um short com estampa da Coca-cola, passando em frente a um posto de gasolina da Texaco. E no para-choque do caminhão se lê: "Do destino ninguém foge". Alguns populares que conversam com Tião - às vezes olhando diretamente para a câmera e, com isso, quebrando a ilusão naturalista - denunciam, por sua vez, o descalabro de leis territoriais que favorecem apenas os ricos. Mas ele não lhes dá ouvidos, já que - diz - “a lei é a lei”, e o fato de não lhes dar ouvidos acaba por acentuar o que os nativos dizem.

$\mathrm{Na}$ sequência, duas cenas contrastam com violência - a cena idílica do casal em uma rede, debaixo do caminhão, e a da despedida violenta de Iracema, que não quer descer do caminhão. "Eu não vou ficar aqui nessa porra de boate escrota", protesta, mas acaba tendo de ceder, entre muitos outros palavrões. Ela volta para um bordel e, com uma amiga, é contratada por um piloto para, supostamente, fazer programa na fazenda de "um americano". Voam então em um pequeno avião ao som de uma viola nordestina, com imagens aéreas do desmatamento. Chegam a um lugar que é um entreposto de trabalhadores escravizados, aos quais elas se juntam, depois de apanharem dos capangas. Sob protestos, sobem no caminhão "pau-de-arara" e se veem abandonadas na mata. Novamente sozinha, Iracema encontra uma senhora que lhe oferece ensino de trabalhos manuais. Ela, à maneira de Macunaíma (então recentemente renascido na pele de Grande Otelo, no filme de Joaquim Pedro de Andrade), responde: "Eu já tô velha pra esse negócio. Deus não quis, minha sina é outra, correr mundo!’ Iracema aparece então em um baile em que se destacam novamente os rostos das pessoas e as cores fortes do cenário. $\mathrm{Na}$ parede 
do bar, provavelmente cheio de menores de idade, se lê: "É expressamente proibido demenores neste recinto". Também chama a atenção que, a cada nova tomada, Iracema vista uma roupa extravagante diferente. Pode ser vista oferecendo café a um grupo de peões construindo uma ponte de madeira, bem como brigando aos gritos e pancadas com uma mulher em disputa por um homem.

8. As cenas finais são particularmente impressionantes porque feitas sob o efeito de álcool em um bordel de beira de estrada, quando Tião Brasil Grande reencontra Iracema, suja e com um dente a menos. Tião para seu caminhão na poeira e vai ao encontro das prostitutas em frente a um casebre, perguntando: “Tem um cachacinha aî? Como vão as brima?”. Elas, completamente bêbadas, dão gargalhadas, mas Tião aparenta não reconhecer Iracema, que se joga sobre ele e exclama: “Tião! Você não é o Tião Brasil Grande?”, ao que ele responde: “Grande, cada vez maior e sempre pra frente!” Quando então se dirige a ela, pergunta: “Tu não é a Jurema?”, que é seu modo de se mostrar distante da menina. No diálogo ébrio, ele diz: "Tu tá mais feia!" e ela responde, rindo: "Você, quanto mais velho, mais bonito fica!".

O protagonista anuncia então que vai levar gado para o Acre, enquanto rechaça os pedidos de carona de Iracema. Cínico, exclama do caminhão, às gargalhadas: "Na volta te pego! Vai preparando as alianças!”. Com uma bota só, o dente a menos, suja e maltrapilha, Iracema corre atrás do caminhão, no meio da poeira, rindo e lançando impropérios ao caminhoneiro branco do sul. E, assim como a narrativa começa com o ruído do motor do barco e os rostos dos ribeirinhos aculturados, termina com o ronco do caminhão misturado às vozes das prostitutas da Transamazônica, xingando sem peias o Brasil Grande.

9. Se algo é possível afirmar sobre os planos de viagem de Bodanzky, Senna e Gauer para a aventura na selva, "no meio daquele fogaréu", é que os próprios viajantes saíram modificados da experiência do encontro de uma equipe de cinema com a vida palpitante da população local, no exato momento em que civilização e barbárie se confrontam e se hibridizam ali de modo irreversível. Perdem-se os parâmetros - ainda uma vez - para dizer o que é civilização e o que é barbárie: a civilização vista como a documentação, o arquivo, e a barbárie como a ficção, e vice-versa, de maneira indecidível. 
Pode-se dizer igualmente que o filme é resultado da "sorte" que tocou a equipe enxuta de brasileiros e alemães, a partir do projeto de Bodanzky e Senna, de pô-la à solta no mundão amazônico da época da construção da absurda estrada. Quais as estratégias utilizadas para fazer da aventura um road-movie inovador, diverso de tudo o que se fazia no cinema brasileiro do período, marcadamente alegórico? Sou levado a associá-lo, em sua radical diferença, aos flertes críticos de Joaquim Pedro de Andrade, no mesmo período, com a pornochanchada, gênero que sustentou a produção de cinema comercial nos anos 60 e 70 . Porque há um deleite comum pelo grotesco, pela linguagem obscena em suas diferentes abordagens do "mundo cão". E porque na câmara que mostra Iracema - a bela indiazinha de Belém vivida por Edna de Cássia (encontrada em um show radiofônico de calouros na capital paraense) que detesta os índios e que o protagonista às vezes chama de Jurema - há um claro deleite sensual, que se repete no olhar ao mesmo tempo irônico e ufano de Pereio como "Tião Brasil Grande". É o que também ocorre com as mulheres de Guerra conjugal (1975) aos olhos do rábula Osíris (Lima Duarte) ou com a melancia de Vereda tropical aos olhos do doutorando e professor de literatura (Cláudio Cavalcanti).

Da literatura ao cinema do lixo. Da lixeratura ao cinema: luxolixo - como no poema concreto, indecidivelmente híbridos: realidadeficção. 
Bibliografia:

AGUILAR, Gonzalo. ¿Quién le teme al realismo? (Sobre el uso de determinados conceptos de la crítica actual). In: ANTELO, R.; REALES, L. Argentina. Texto tempo movimento. Florianópolis: Letras Contemporâneas, 2011.

AIRA, César. Nouvelles impressions du Petit Maroc. Trad. Christophe Josse. Saint-Nazaire: M.E.E.T-Arcane 17, 1991.

FOUCAULT, Michel. A escrita de si (1983). In: O que é um autor? Lisboa: Passagens, 1992.

GRAMUGLIO, Maria Tereza. Introducción. In: GRAMUGLIO, M. T.; JITRIK, N. Historia crítica de la literatura argentina. El imperio realista. Buenos Aires: Emecé, 2002.

LUDMER, Josefina. "Literaturas pós-autônomas". Trad. Flavia Cera. Sopro 20. Panfleto político-cultural. Desterro, janeiro de 2010. Disponível em: www.culturaebarbarie.org/sopro Acesso em: 20/jan/2010.

SAER, Juan José. El concepto de ficción. Punto de Vista no 40, Buenos Aires, julio-setiembre 1991.

SANTIAGO, Silviano. Histórias mal contadas. Rio de Janeiro: Rocco, 2005.

Nas malhas da letra. Rio de Janeiro: Rocco, 2002. 